\title{
Multilevel Societies in Primates and Other Mammals: Introduction to the Special Issue
}

\author{
Cyril C. Grueter • Ikki Matsuda • Peng Zhang • Dietmar Zinner
}

Received: 3 April 2012 / Accepted: 7 April 2012 /Published online: 8 June 2012

(C) The Author(s) 2012. This article is published with open access at Springerlink.com

Murdoch (1981) remarked that nowhere on Earth do people live regularly in isolated families. The habitual formation of superfamily level groupings is one of the unmistakable universals of human sociality. Males and females within these higher level groupings are connected via kinship and affinity ties, and affiliative and cooperative bonds reach far beyond the nuclear family unit (Rodseth et al. 1991; Wiessner 1977). Although interunit encounters are usually circumvented or characterized by animosity because of mating or resource competition in many nonhuman primates (Cheney 1987; Fashing 2001), some primates such as hamadryas baboons (Papio hamadryas), geladas (Theropithecus gelada), snub-nosed monkeys (Rhinopithecus spp.), and proboscis monkeys (Nasalis larvatus) (for an exhaustive list, see Grueter et al. 2012) exhibit a social arrangement in which regular or constant proximity as well

C. C. Grueter $(\bowtie)$

School of Anatomy, Physiology and Human Biology, The University of Western Australia, Crawley, WA 6009, Australia

e-mail: cyril.grueter@uwa.edu.au

C. C. Grueter

Anthropological Institute and Museum, University of Zürich-Irchel, 8057 Zürich, Switzerland

I. Matsuda

Primate Research Institute, Kyoto University, Inuyama 484-8506, Japan

P. Zhang

Anthropology Department, Sun Yat-sen University, Guangzhou 510275, China

D. Zinner

Cognitive Ethology Laboratory, German Primate Center, 37077 Göttingen, Germany

D. Zinner

Courant Research Centre "Evolution of Social Behavior”, University of Göttingen, 37077 Göttingen, Germany 
as coordinated activity among subunits is the norm. This type of social organization has been termed multilevel, nested, or modular. The phenomenon of social modularity is not restricted to the primate order. Similarly structured societies can be observed in other mammals, most notably African elephants (Loxodonta africana: de Silva and Wittemyer 2012; Moss and Poole 1983; Wittemyer et al. 2005), Asian elephants (Elephas maximus: de Silva and Wittemyer 2012), plains zebras (Equus burchelli: Rubenstein and Hack 2004), khulans (Equus hemionus: Feh et al. 2001), prairie dogs (Cynomys ludovicianus: Hoogland 1995), sperm whales (Physeter macrocephalus: Whitehead et al. 1991, 2012), and killer whales (Orcinus orca: Baird 2000).

Stammbach (1987) was the first to compare the social organization and social interactions of baboon species exhibiting multilevel societies. Later, Grueter and Zinner (2004) elaborated on this earlier review by contrasting modularity of papionins with that of snub-nosed monkeys - a hitherto poorly known primate radiationand synthesizing information on various aspects of their respective social systems. With the present special issue, we have brought together experts in the field of multilevel sociality for the first time with the aim of tackling the issue of the evolution of multilevel societies from various angles and adopting a broad-scale approach by including papers on species other than primates as well as contributions by sociocultural anthropologists. Here we aim to introduce the phenomenon of multilevel societies and give a synopsis of the range of topics covered by the contributions to this theme issue.

Multilevel societies are typically characterized by discrete social stratification with at least one stable core unit. de Silva and Wittemyer (2012), however, call for a relaxed definition of multilevel societies to encompass not only species showing such nestedness, but also systems in which an individual associates with more than one set of companions and societies in which levels are less clearly delineated and transition more gradually. It has become apparent that in nonprimate multilevel societies, such as those of cetaceans and proboscideans, boundaries between tiers are not as sharp as in primates, with the possible exception of uakaris (Bowler et al. 2012). In primates, the most common module at the base of a multilevel society is a one-male-multifemale unit (OMU) or "harem," with all-male units often being in the neighborhood (Grueter and Zinner 2004). In other mammals, the core unit can also be closely associated breeding females, as seen in elephants (Wittemyer et al. 2005) or sperm whales (Whitehead 2003; Whitehead et al. 1991, 2012). Although a classic multilevel society is typically composed of two to four hierarchically inclusive social tiers (Kawai et al. 1983; Ren et al. 2000), in some species, such as elephants, the picture is more complicated, with up to six identified tiers (Wittemyer et al. 2005). Hamadryas baboons - at least the Filoha population - also seem to have an impressive five different levels (Schreier and Swedell 2012). More thorough research may well reveal previously hidden levels of complexity in the architecture of multilevel social systems.

Multilevel societies are superficially the most complex social systems found among primates or mammals in general. To understand how these societies work, we need to investigate how social interactions and relationships are patterned both within and between social elements, and analyze the kinship structure of the population, i.e., the degree of genetic relatedness among individuals within and between 
units, which is contingent on dispersal patterns. The diversity in the cohesiveness and nature of intrafamily social bonds - with some of the core units being female-bonded and others cross-sex bonded (Grueter et al. 2012; Matsuda et al. 2012; Zhang et al. 2012) - adds to the intricacy of the system.

A prerequisite for understanding multilevel sociality is a formal analysis of the composition of the group. Social levels need to be clearly defined and boundaries delineated (Kawai et al. 1983; Snyder-Mackler et al. 2012). State-of-the-art tools such as social network analysis and hierarchical cluster analysis facilitate analyses of the structural properties of multilevel organizations (Matsuda et al. 2012; SnyderMackler et al. 2012; Wittemyer et al. 2005; Yeager 1990; Zhang et al. 2012; see also Schweizer 1997). However, even identifying a multilevel system as such has sometimes proven difficult, as it requires good observation conditions (open terrain and terrestrial behavior) at the level of the individual or at least the unit (Bowler et al. 2012). Given the sheer size of many multilevel primate groups (often with up to several hundred members), achieving individual identification is a challenge under wild and unprovisioned conditions. Indeed, some multilevel societies were formerly considered to be macaque-like multimale-multifemale groups (Kawabe and Mano 1972; Li et al. 1982). Data on the spatiotemporal distribution of individuals can help to detect the boundaries of the core units (Grueter et al. in press). Recognizing the boundaries of intermediate levels (if present) is much more difficult, especially in gelada and Guinea baboon groups which fission and fuse throughout the day in an almost seamless manner (Dunbar 1993; Patzelt et al. 2011; Snyder-Mackler et al. 2012).

Multilevel societies might easily be confounded with aggregations, i.e., situations in which animal units are attracted by extrinsic stimuli such as clumped food or roosts. Although a number of elephant seal harems sharing a beach or western gorillas units coming into a bai to forage might on the surface resemble a multilevel society, these are in fact nonmutualistic assemblages in which individuals do not actively maintain proximity as a means of obtaining benefits from each other's presence ( $c f$. Connor 2000). Similarly, hamadryas baboon gravitate to scarce sleeping sites in their habitat, but the ensuing troop level does not qualify to be considered a "social" unit in the strict sense. Similarly, when two multimale-multifemale groups of olive baboons share a rocky cliff as a sleeping site in areas without suitable trees, we would not classify this as a multilayered organization. It is also worth noting that multilevel societies are not the same as fission-fusion systems. Fission-fusion is common in many multilevel societies, e.g., sperm whales (Christal et al. 1998), hamadryas baboons (Kummer and Abegglen 1978), or snub-nosed monkeys (Ren et al. 2012), but fission-fusion dynamics can characterize both species living in multilevel societies and multimale-multifemale groups (Grueter et al. 2012).

Although a single social grouping serves a variety of functions in nonmodular species (predator and food defense, social bonds and cooperation, mating and reproduction), the different functional units of the society are clearly segregated in multilevel species (Swedell and Plummer 2012). Socioecological theory provides a framework for an attempt to understand the functionality behind these structures, as the same factors that drive socialization in nonmodular species may also have explanatory power in a multilevel setting, e.g., predation avoidance (Matsuda et al. 2010; Yeager 1992; Whitehead et al. 2012), facilitation of foraging (Whitehead 
2003), or conspecific threat (Grueter and van Schaik 2010). Each level has evolved in response to a different compilation of cost-benefit tradeoffs (Wittemyer et al. 2005), but any endeavor aimed at identifying the function of the different social tiers is complicated by the fact that we must distinguish among several targets of ultimate reasoning, i.e., 1) evolutionary pathways: multilevel systems can evolve as a result of splitting of large mixed-sex groups or an amalgamation of discrete family units, 2) the emergent factors keeping the system in place, and 3) the adaptive significance of fission-fusion (if prevalent) among constituent units. For example it is assumed that compression of large numbers of individuals into a localized resource in hamadryas baboons has created a harassment-prone environment leading to substructuring (evolution). Male bonds across units contribute to uphold the system (emergent factor), while the patchy nature of food resources and restricted availability of roosting sites leads to fissioning and fusioning (Grueter et al. 2012). There are examples of all three analytical approaches in this issue: Grueter et al. (2012) attempt to depict the most parsimonious evolutionary pathways to modularity in different primate lineages. A reconstruction of ancestral social states is always fraught with a degree of "paleo-poetry," but the use of a combination of phylogenetic, morphological, peleoenvironmental, and socioecological evidence can significantly narrow down the options. Bowler et al. (2012) rely on proximity measures to identify the social organization of uakaris, whereas Zhang et al. (2012) rely on such measures to deduce affiliation patterns within OMUs of Rhinopithecus. Finally, Ren et al. (2012) describe fission-fusion dynamics within a society of Rhinopithecus and explain temporary group splitting with optimization of access to seasonal foods.

Given the tremendous variety of habitats in which multilevel sociality has evolved, pinning it down to a universal environmental driver is utopian. Environmental features can constrain the evolution of modularity (Grueter and van Schaik 2010), but modularity is also the outcome of individual behavioral strategies. The explanatory framework for multilevel sociality contains recurring themes that are of great importance for comparative primatologists and anthropologists, e.g., conspecific threat and infanticide (Grueter and van Schaik 2010; Henzi and Barrett 2003), band-level male-male cooperation (Hill et al. 2009; Jolly and Phillips-Conroy 1998), and a tolerance or alliance network among some groups caused by female exogamy (Chagnon 1992; Chapais 2008). Mutualistic benefits accrued through collective defense, i.e., experiencing a reduced probability of being challenged when with other units (Colmenares 2004; Rubenstein and Hack 2004), may have substantial explanatory power for the emergence of modularity. Evidence for cooperation in the defense of group integrity against satellite males is still circumstantial in multilevel societies (Dunbar and Dunbar 1975; Krzton 2011; Zhao and Li 2009), but this needs to be rigorously assessed through long-term field programs.

Studying the nuances of multilevel sociality in primates also has potentially important implications for hominin behavioral evolution. Chimpanzees may well be an apt referential model that helps us to characterize the social system of the last common ancestor ( $c f$. McGrew 2010), but for the transformation of mixed sex groups to embedded pair bonds - the modal system in humans - we can learn a great deal from primates living in multilevel societies (Swedell and Plummer 2012). Male kinbonding is another hallmark of human sociality that appears to have its analogue in hamadryas clans (Swedell and Plummer 2012). Rodseth (2012) devalues the 
importance of marital ties as the linchpin of human societies by raising awareness for the integral role that male social solidarity plays in human societies, with conjugal bonds sometimes being nothing but mere appendages to an all-male association. Layton et al. (2012) attempt to trace the appearance of band organization in modern human hunter-gatherers via inferences from brain evolution, ethnography, and the movement of stone tools beyond the source of their raw materials at various periods in prehistory.

Although hamadryas baboons, which are famous for their multilevel system, were among the first primate species to be studied in the wild (Kummer 1968, 1995), the dynamics of most multilevel societies are still poorly understood. There are many possible avenues for further research, both in the laboratory and the field. For some species, such as uakaris (Bowler et al. 2012), drills (Mandrillus leucophaeus: Astaras 2009; Astaras et al. 2008), doucs (Pygathrix spp.: Rawson 2009), and golden langurs (Trachypithecus geei: Mukherjee and Saha 1974), we have only limited field data on social organization and structure and much more empirical evidence for the existence of modularity is needed, as well as data on genetic relationships among individuals of all levels of a nested society. There is a clear need for more field studies on these neglected primate taxa. For colobines in particular, we need to gain a clearer understanding of the network structure and links across social levels within modular societies. The use of artificial approaches such as agent-based modeling may be another promising way to tackle the analysis of determinants of multilevel organizations (Zinner and Hammerschmidt 2008). The cooperative potential among coresiding males in multilevel societies may be latent, but might be activated by artificial stimuli (if ethically justifiable), as shown by actively coordinated group reactions to trapping (Jolly and Phillips-Conroy 1998).

Band formation in some multilevel species, e.g., colobines, has been argued to represent an adaptation to enhanced threat from conspecifics (Grueter and van Schaik 2010). Another possible explanation that has not yet received empirical scrutiny is that band formation may be a strategy to facilitate allocare in species living under precarious environmental conditions, resulting in mutualistic alleviation of female energetic stress. If this turns out to have explanatory power, then it may have implications for our understanding of the evolution of allocare and cooperative breeding in humans (Hrdy 2009). Almost untouched is the question of what predictions we have concerning individual recognition, group coordination, communication, cognitive skills, decision making, and disease transmission in multilevel organizations (Fischer and Zinner 2011; Sueur et al. 2011). Also remarkable and requiring explanation is that most or all primate species that live in large multilevel societies, e.g., geladas, snub-nosed monkeys, proboscis monkeys, douc langurs, exhibit striking facial and bodily coloration as well as other ornaments. These conspicuous signals may be adaptive in primates living in small cohesive groups where individual recognition is the primary means by which animals "know" one another. However, in large modular groups — particularly groups where membership is not always constant - individuals require alternative ways of "knowing" each another and assessing each other's quality and status. It has been suggested (Bergman et al. 2009; Setchell and Kappeler 2003) that living in large groups selects for such conspicuous ornaments (presumably sexually selected signals of quality) because individual recognition is no longer an option. 
It is obvious that our knowledge of these intriguing societies is still limited. Unfortunately, most species showing multilevel sociality are endangered, and pristine conditions allowing the complexities of multilevel systems to unfold unhampered are becoming rare. Bands of snub-nosed monkeys often occur in fragmented habitats with limited or absent connectivity with neighboring bands (Grueter et al. in press). Bands/populations of proboscis monkeys have become locally extinct as a result of habitat loss (Sha et al. 2008). Heavy modern whaling in the Pacific may have destroyed the integrity of many sperm whale social units (Whitehead et al. 2012). Poaching has altered the expression of the elephant social system (Foley 2002). We hope that this special issue will spark interest among primatologists, mammalogists and biocultural anthropologists to embark on studies pertaining to the structure and evolution of these multilayered societies and thereby not only contribute to a better understanding of the evolutionary drivers of human social evolution, but also raise awareness for the plight of this unique evolutionary heritage.

Acknowledgments We thank Joanna Setchell for making this special issue come true and all the people who helped with reviewing manuscripts submitted to this special issue: Kim Hill, Kristen Hawkes, Noah Snyder-Mackler, Peter Fashing, Craig Kirkpatrick, Juichi Yamagiwa, Bernard Chapais, Robin Dunbar, Filippo Aureli, Mark Timothy Bowler, James Higham, Amy Schreier, Yongcheng Long, Songtao Guo, Ramesh Boonratana, Richard Connor, Cedric Sueur, Thore Bergman, Caroline Ross, Russell Hill, Larissa Swedell, Katrin Fehl, Bernhard Voelkl, Kazunori Yamada, Siva Sundaresan, Patrick Chiyo, Thomas Gregor, Robert Seyfarth, Jacinta Beehner, Annika Patzelt, Bruna Martins Bezerra, and Carel van Schaik. We also thank Dennis Galvez for his editorial assistance. We are also grateful to all the participants of our Symposium at the 23rd International Society of Primatology Congress in Japan, September 12-18, 2010 for their excellent series of talks, constructive comments, and discussions.

Open Access This article is distributed under the terms of the Creative Commons Attribution License which permits any use, distribution, and reproduction in any medium, provided the original author(s) and the source are credited.

\section{References}

Astaras, C. (2009). Ecology and status of the drill (Mandrillus leucophaeus) in Korup National Park, southwest Cameroon: Implications for conservation. Ph.D. thesis, Georg-August-University of Göttingen.

Astaras, C., Mühlenberg, M., \& Waltert, M. (2008). Note on drill (Mandrillus leucophaeus) ecology and conservation status in Korup National Park, Southwest Cameroon. American Journal of Primatology, $70,306-310$.

Baird, R. (2000). The killer whale: Foraging specializations and group hunting. In J. Mann, R. C. Connor, P. Tyack, \& H. Whitehead (Eds.), Cetacean Societies (pp. 127-153). Chicago: University of Chicago Press.

Bergman, T. J., Ho, L., \& Beehner, J. C. (2009). Chest color and social status in male geladas (Theropithecus gelada). International Journal of Primatology, 30, 791-806.

Bowler, M., Knogge, C., Heymann, E. W., \& Zinner, D. (2012). Multilevel societies in New World primates? Flexibility may characterize the organization of Peruvian red uakaris (Cacajao calvus ucayalii). International Journal of Primatology, 33. doi:10.1007/s10764-012-9603-6.

Chagnon, N. A. (1992). Yanomamö. Fort Worth: Harcourt Brace College.

Chapais, B. (2008). Primeval kinship: How pair-bonding gave birth to human society. Cambridge, MA: Harvard University Press.

Cheney, D. (1987). Interactions and relationships between groups. In B. B. Smuts, D. L. Cheney, R. M. Seyfarth, R. W. Wrangham, \& T. T. Struhsaker (Eds.), Primate societies (pp. 267-281). Chicago: University of Chicago Press. 
Christal, J., Whitehead, H., \& Lettevall, E. (1998). Sperm whale social units: variation and change. Canadian Journal of Zoology, 76, 1431-1440.

Colmenares, F. (2004). Kinship structure and its impact on behavior in multilevel societies. In B. Chapais \& C. M. Berman (Eds.), Kinship and behavior in primates (pp. 242-270). Oxford: Oxford University Press.

Connor, R. (2000). Group living in whales and dolphins. In J. Mann, R. C. Connor, P. L. Tyack, \& H. Whitehead (Eds.), Cetacean societies (pp. 199-218). Chicago: University of Chicago Press.

de Silva, S., \& Wittemyer, G. (2012). A comparison of social organization in Asian and African savannah elephants. International Journal of Primatology, 33. doi:10.1007/s10764-011-9564-1.

Dunbar, R. I. M. (1993). Social organization of the gelada. In N. G. Jablonski (Ed.), Theropithecus: The rise and fall of a primate genus (pp. 425-439). Cambridge, UK: Cambridge University Press.

Dunbar, R. I. M., \& Dunbar, E. P. (1975). Social dynamics of gelada baboons. Basel: Karger.

Fashing, P. J. (2001). Male and female strategies during inter-group encounters in guerezas (Colobus guereza): evidence for resource defence mediated through males and a comparison with other primates. Behavioral Ecology and Sociobiology, 50, 219-230.

Feh, C., Munkhtuya, B., Enkhbold, S., \& Sukhbaatar, T. (2001). Ecology and social structure of the Gobi khulan Equus hemionus subsp in the Gobi B National Park, Mongolia. Biological Conservation, 101, 51-61.

Fischer, J., \& Zinner, D. (2011). Communication and cognition in primate group movement. International Journal of Primatology, 32, 1279-1295.

Foley, C. A. H. (2002). The effects of poaching on elephant social systems. Princeton, NJ: Princeton University Press.

Grueter, C. C., \& Zinner, D. (2004). Nested societies: convergent adaptations in snub-nosed monkeys and baboons? Primate Report, 70, 1-98.

Grueter, C. C., \& van Schaik, C. P. (2010). Evolutionary determinants of modular societies in colobines. Behavioral Ecology, 21, 63-71.

Grueter, C. C., Chapais, B., \& Zinner, D. (2012). Evolution of multilevel societies in nonhuman primates and humans. International Journal of Primatology, 33.

Grueter, C. C., Li, D., Ren, B., \& Wei, F. (2012). Insights into the social system of black-and-white snubnosed monkeys. In C. L. Tan, C. C. Grueter, \& B. W. Wright (Eds.), Odd-nosed monkeys: Recent advances in the study of the forgotten colobines. New York: Springer.

Grueter, C. C., Kirkpatrick, R. C., Wright, B. W., \& Tan, C. L. (in press). The natural history of the odd-nosed monkeys: Current state of research and conservation. In C. L. Tan, C. C. Grueter, \& B. W. Wright (Eds.), Odd-nosed monkeys: Recent advances in the study of the forgotten colobines. New York: Springer.

Henzi, P., \& Barrett, L. (2003). Evolutionary ecology, sexual conflict, and behavioral differentiation among baboon populations. Evolutionary Anthropology, 12, 217-230.

Hill, K., Barton, M., \& Hurtado, A. M. (2009). The emergence of human uniqueness: characters underlying behavioral modernity. Evolutionary Anthropology, 18, 187-200.

Hoogland, J. (1995). The black-tailed prairie dog: Social life of a burrowing mammal. Chicago: University of Chicago Press.

Hrdy, S. B. (2009). Mothers and others: the evolutionary origins of mutual understanding. Cambridge, MA: Belknap Press.

Jolly, C. J., \& Phillips-Conroy, J. E. (1998). Taxon-specific reactions to trapping among Ethiopian baboons. American Journal of Physical Anthropology, 105(Supplement 26), 129

Kawabe, M., \& Mano, T. (1972). Ecology and behaviour of the wild proboscis monkey, Nasalis larvatus (Wermb.) in Sabah, Malaysia. Primates, 13, 213-227.

Kawai, M., Dunbar, R. I. M., Ohsawa, H., \& Mori, U. (1983). Social organization of gelada baboons: social units and definitions. Primates, 24, 13-24.

Kummer, H. (1968). Social organization of hamadryas baboons: A field study. Basel: Karger.

Kummer, H. (1995). In quest of the sacred baboon: A scientist's journey. Princeton: Princeton University Press.

Kummer, H., \& Abegglen, J. J. (1978). Gesellschaftsordnung bei Mantelpavianen. In R. A. Stamm \& H. Zeier (Eds.), Die Psychologie des 20. Jahrhunderts. Band VI: Lorenz und die Folgen (pp. 163-176). Zurich: Kindler.

Krzton, A. (2011). Coordinated patrolling behavior of unrelated breeding males in the golden snub-nosed monkey (Rhinopithecus roxellana). American Journal of Physical Anthropology, 144(Supplement 52), 193.

Layton, R., O’Hara, S., \& Bilsborough, A. (2012). Antiquity and social functions of multilevel social organization among human hunter-gatherers. International Journal of Primatology, 33.

Li, Z.-X., Ma, S.-L., Hua, C.-H., \& Wang, Y.-X. (1982). The distribution and habit of the Yunnan golden monkey, Rhinopithecus bieti. Journal of Human Evolution, 11, 633-638. 
Matsuda, I., Tuuga, A., \& Higashi, S. (2010). Effects of water level on sleeping-site selection and intergroup association in proboscis monkeys: why do they sleep alone inland on flooded days? Ecological Research, 25, 475-482.

Matsuda, I., Zhang, P., Swedell, L., Mori, U., Tuuga, A., Bernard, H., \& Sueur, C. (2012). Comparisons of intraunit relationships in nonhuman primates living in multilevel social systems. International Journal of Primatology, 33. doi:10.1007/s10764-012-9616-1.

McGrew, W. C. (2010). In search of the last common ancestor: new findings on wild chimpanzees. Proceedings of the Royal Society of London B: Biological Sciences, 365, 3267-3276.

Moss, C. J., \& Poole, J. H. (1983). Relationships and social structure in African elephants. In R. A. Hinde (Ed.), Primate social relationships: An integrated approach (pp. 315-325). Oxford: Blackwell.

Mukherjee, R., \& Saha, S. (1974). The golden langurs (Presbytis geei Khajuria, 1956) of Assam. Primates, 15, 327-340.

Murdoch, G. P. (1981). Atlas of world cultures. Pittsburgh: University of Pittsburgh Press.

Patzelt, A., Zinner, D., Fickenscher, G., Diedhiou, S., Camara, B., Stahl, D., \& Fischer, J. (2011). Group composition of Guinea baboons (Papio papio) at a water place suggests a fluid fission-fusion social organization. International Journal of Primatology, 32, 652-668.

Rawson, B. M. (2009). The socio-ecology of the black-shanked douc (Pygathrix nigripes) in Mondulkiri Province, Cambodia. Ph.D. thesis, Australian National University, Canberra.

Ren, B., Li, D., Garber, P. A., \& Li, M. (2012). Fission-fusion behavior in Yunnan snub-nosed monkeys (Rhinopithecus bieti) in Yunnan, China. International Journal of Primatology, 33. doi:10.1007/ s10764-012-9586-3.

Ren, R., Yan, K., Su, Y., Zhou, Y., Li, J., Zhu, Z., Hu, Z., \& Hu, Y. (2000). A field study of the society of Rhinopithecus roxellanae. Beijing: Beijing University Press.

Rodseth, L. (2012). From bachelor threat to fraternal security: male associations and modular organization in human societies. International Journal of Primatology, 33. doi:10.1007/s10764-012-9593-4.

Rodseth, L., Wrangham, R. W., Harrigan, A. M., \& Smuts, B. B. (1991). The human community as a primate society. Current Anthropology, 32, 221-254.

Rubenstein, D. I., \& Hack, M. (2004). Natural and sexual selection and the evolution of multi-level societies: Insights from zebras with comparisons to primates. In P. M. Kappeler \& C. P. van Schaik (Eds.), Sexual selection in primates: New and comparative perspectives (pp. 266-279). New York: Cambridge University Press.

Schreier, A. L., \& Swedell, L. (2012). The socioecology of network scaling ratios in the multilevel society of hamadryas baboons. International Journal of Primatology, 33. doi:10.1007/s10764-011-9572-1.

Schweizer, T. (1997). Embeddedness of ethnographic cases: a social network perspective. Current Anthropology, 38, 739-760.

Setchell, J. M., \& Kappeler, P. M. (2003). Selection in relation to sex in primates. Advances in the Study of Behavior, 33, 87-173.

Sha, J. C. M., Bernard, H., \& Nathan, S. (2008). Status and conservation of proboscis monkeys (Nasalis larvatus) in Sabah, East Malaysia. Primate Conservation, 23, 107-120.

Snyder-Mackler, N., Beehner, J. C., \& Bergman, T. J. (2012). Defining higher levels in a gelada multilevel society. International Journal of Primatology, 33. doi:10.1007/s10764-012-9584-5.

Stammbach, E. (1987). Desert, forest and montane baboons: Multilevel societies. In B. B. Smuts, D. L. Cheney, R. M. Seyfarth, R. W. Wrangham, \& T. T. Struhsaker (Eds.), Primate societies (pp. 112-120). Chicago: University of Chicago Press.

Sueur, C., King, A. J., Conradt, L., Kerth, G., Lusseau, D., Mettke-Hofmann, C., Schaffner, C. M., Williams, L., Zinner, D., \& Aureli, F. (2011). Collective decision-making and fission-fusion dynamics: a conceptual framework. Oikos, 120, 1608-1617.

Swedell, L., \& Plummer, T. (2012). A baboon multilevel society as a model for early hominin evolution. International Journal of Primatology, 33. doi:10.1007/s10764-012-9600-9.

Whitehead, H., Waters, S., \& Lyrholm, T. (1991). Social organization of female sperm whales and their constant companions and casual acquaintances. Behavioral Ecology and Sociobiology, 29, 385-389.

Whitehead, H., Antunes, R., Gero, S., Wong, S. N. P., Engelhaupt, D., \& Rendell, L. (2012). Multilevel societies of female sperm whales (Physeter macrocephalus) in the Atlantic and Pacific: why are they so different? International Journal of Primatology, 33. doi:10.1007/s10764-012-9598-z.

Wittemyer, G., Douglas-Hamilton, I., \& Getz, W. (2005). The socioecology of elephants: analysis of the processes creating multitiered social structures. Animal Behaviour, 69, 1357-1371.

Whitehead, H. (2003). Sperm whales: Social evolution in the ocean. Chicago: University of Chicago Press. Wiessner, P. (1977). Hxaro: A regional system of reciprocity for reducing risk among the !Kung San. Ann Arbor, MI: University Microfilms. 
Yeager, C. P. (1990). Proboscis monkey (Nasalis larvatus) social organization: group structure. American Journal of Primatology, 20, 95-106.

Yeager, C. P. (1992). Proboscis monkey (Nasalis larvatus) social organization: nature and possible functions of intergroup paterns of association. American Journal of Primatology, 26, 133-137.

Zhang, P., Li, B., Qi, X, MacIntosh, A. J., \& Watanabe, K. (2012). A proximity-based social network of a group of Sichuan snub-nosed monkeys (Rhinopithecus roxellana). International Journal of Primatology, 33. doi:10.1007/s10764-012-9608-1

Zhao, D., \& Li, B. (2009). Do deposed adult male Sichuan snub-nosed monkeys Rhinopithecus roxellana roam as solitary bachelors or continue to interact with former band members? Current Zoology, 55, 235-237.

Zinner, D., \& Hammerschmidt, K. (2008). Modelling the evolution of hamadryas baboon social system. Primate Eye, 96, 310-311. 